\title{
O Tratamento da Ansiedade por Intermédio da Acupuntura: Um Estudo de Caso
}

\author{
The Treatment of Anxiety Through Acupunture: \\ A Case Study \\ El Tratamiento de la Ansiedad por Intermedio de la \\ Acupuntura: Un Estudio de Caso
}

André Luiz Picolli da Silva

Universidade Federal do Pará 
Resumo: A ansiedade é um fenômeno amplamente estudado no ocidente pela Psicologia, pela psicanálise e pela Medicina. Caracteriza-se por um estado subjetivo desagradável de inquietação, tensão e apreensão. Embora a terminologia ansiedade não seja encontrada na literatura da medicina tradicional chinesa, os sintomas descritos são amplamente estudados. Tal literatura considera essa patologia metaforicamente uma desarmonia do espírito, e apresenta uma série de possibilidades de intervenções por técnicas tradicionais como a acupuntura. O objeto deste artigo é relatar o tratamento realizado por meio da acupuntura a uma paciente que apresentava transtorno de ansiedade. Após a identificação dos sintomas de ansiedade, realizados pela queixa da paciente e pela análise clínica embasada no DSM IV, foram realizadas 10 sessões de acupuntura tradicional chinesa, utilizando como referencial teórico a literatura clássica da medicina chinesa. Os resultados obtidos foram a diminuição parcial dos sintomas a partir da quarta sessão e uma significativa melhora da paciente, com o relato do alívio dos sintomas a partir da sexta sessão de tratamento. Palavras-chave: Acupuntura. Ansiedade. Terapia complementar. Saúde.

Abstract: Anxiety is a phenomenon widely studied in the West by psychology, psychoanalysis and medicine. It is characterized by an unpleasant subjective state of worry, tension and apprehension, in which it is difficult to relax. Although the terminology anxiety is not found in the literature of Chinese traditional medicine, the described symptoms are studied widely. Such literature considers that pathology metaphorically as a discord of the spirit and presents a series of possibilities of interventions for traditional techniques as the acupuncture. The objective of this article was the treatment accomplished through acupuncture to a patient that presented anxiety disorder. After the confirmation of the diagnosis 10 sessions of Chinese traditional acupuncture were accomplished, using as theoretical reference the classic literature of Chinese medicine. The results were the partial suppression of the symptoms starting from the fourth session and a total recovery of the patient by the disappearance of all of the symptoms starting from the sixth treatment session.

Keywords: Acupuncture. Anxiety. Complementary therapy. Health.

Resumen: La ansiedad es un fenómeno ampliamente estudiado en el occidente por la Psicología, por el psicoanálisis y por la Medicina. Se caracteriza por un estado subjetivo desagradable de inquietud, tensión y aprehensión. Aunque la terminología ansiedad no sea encontrada en la literatura de la medicina tradicional china, los síntomas descritos son ampliamente estudiados. Tal literatura considera esa patología metafóricamente una desarmonía del espíritu, y presenta una serie de posibilidades de intervenciones por técnicas tradicionales como la acupuntura. El objeto de este artículo es relatar el tratamiento realizado por medio de la acupuntura a una paciente que presentaba trastorno de ansiedad. Después de la identificación de los síntomas de ansiedad, realizados por la queja de la paciente y por el análisis clínico basado en el DSM IV, fueron realizadas 10 sesiones de acupuntura tradicional china, utilizando como referencial teórico la literatura clásica de la medicina china. Los resultados logrados fueron la disminución parcial de los síntomas desde la cuarta sesión y una significativa mejora de la paciente, con el relato del alivio de los síntomas desde la sexta sesión de tratamiento.

Palabras clave: Acupuntura. Ansiedad. Terapia complementar. Salud.

A medicina tradicional chinesa e, mais especificamente, a acupuntura, ainda são campos de estudos pouco conhecidos pelos psicólogos brasileiros. Somente depois da regulamentação do uso da acupuntura como técnica complementar, pelo Conselho Federal de Psicologia, com a Resolução CFP $\mathrm{n}$ 005/2002, foi que a mesma começou a despertar o interesse dos psicólogos que trabalham no âmbito clínico e da saúde.

A acupuntura é um dos muitos elementos que compõem a Medicina Tradicional Chinesa (MTC), que também utiliza práticas como a massagem, a fitoterapia, exercícios físicos e respiratórios, como o tai chi chuan e o qi qong, para promover a saúde física, psíquica e espiritual do indivíduo. De acordo com Campiglia (2004), Vectore (2005) e Silva (2007), a medicina tradicional chinesa e, portanto, a própria acupuntura, se baseia no princípio de que o homem deve estar em harmonia com as forças primordiais da natureza, que os chineses chamam de yin e yang (dois princípios opostos e complementares que compõem todo o universo), sendo que essa harmonia gera um equilíbrio que pode ser traduzido como saúde, e, por sua vez, o desequilíbrio, como doença. O princípio básico da acupuntura sustenta 
que o equilíbrio é mantido no corpo humano por meio do fluxo suave de uma energia denominada pelos chineses qi, bem como pelo fluxo, também suave, pelo corpo, do sangue, denominado pelos chineses como xue. Problemas ambientais, alimentares, emocionais ou espirituais podem causar algum tipo de alteração na circulação do qi e do xue no organismo, originando assim algum tipo de disfunção ou patologia. A partir do momento em que alguma patologia esteja instalada no organismo, uma das formas de eliminá-la ou de minimizá-la seria a inserção de agulhas em pontos específicos do corpo, que tem a propriedade de restabelecer esse fluxo suave, ou seja, pela prática da acupuntura (Silva, 2007; Xinnong, 1999).

Tendo esse princípio como base, qualquer tipo de disfunção ou patologia, como, por exemplo, a ansiedade, pode ser tratada por intermédio da acupuntura; porém, realizar o tratamento de uma patologia como a ansiedade pela acupuntura talvez não seja um procedimento tão simples de realizar como possa parecer em um primeiro momento, porque, na literatura da medicina tradicional chinesa, não existe referência a essa patologia específica, cuja nomenclatura é tipicamente ocidental. A própria ansiedade é um fenômeno ainda insuficientemente compreendido mesmo no ocidente, pois, ao mesmo tempo em que apresenta sintomas específicos, ela própria pode ser entendida como sintoma de outras patologias.

E é a partir desse entendimento (da ansiedade como um sintoma) que é possível traçar paralelos entre o conhecimento ocidental e a acupuntura chinesa. Comparando as sintomatologias descritas, é possível identificar o que os tratados clássicos chineses escreviam sobre o que atualmente se classifica de ansiedade, e, desse modo, realizar no ocidente o tratamento nos moldes descritos pelos princípios tradicionais da China.

\section{O entendimento do fenômeno ansiedade pela ciência ocidental}

A ansiedade há muito já foi identificada na ciência ocidental e bastante estudada pelas áreas da Psicologia, da psicanálise e da Medicina. A ansiedade não é considerada um fenômeno necessariamente patológico, e é mais bem entendida como uma função natural do organismo que permite que o mesmo esteja preparado ou que se prepare para responder da melhor forma possível a uma situação nova e desconhecida ou a uma situação já conhecida e interpretada como potencialmente perigosa. Entretanto, se a ansiedade atingir graus muito elevados e contínuos, ela pode ser considerada prejudicial ao organismo, pois fará com que este permaneça em constante estado de alerta, configurando então, uma situação patológica.

Na ciência ocidental, ainda não se sabe ao certo quais as causas para o surgimento da ansiedade, e, embora os estudos de base biológica estejam avançados, as melhores explicações ainda são as de base psicodinâmica (Kaplan, Sadok, \& Greb, 1997). Para esses autores, ainda é possível fazer uma distinção entre uma ansiedade considerada normal e uma ansiedade patológica, e afirmam que a ansiedade apresenta qualidades de preservação da vida, pois alerta o indivíduo sobre uma possível ameaça interna ou externa. Nesse sentido, ela tem a função de preparar o indivíduo para que este se proteja de uma ameaça ou, em não conseguindo fazê-lo, que pelo menos diminua suas consequências.

Assim, a ansiedade está presente na vida de uma pessoa ao longo de toda a sua existência, e pode ser entendida como um acompanhamento normal das diversas mudanças que ocorrem na vida. Entretanto, tal fenômeno pode apresentar um caráter patológico quando surge como uma resposta 
inadequada, devido a sua intensidade ou duração, perante um determinado estímulo.

Quando a ansiedade se apresenta em uma intensidade ou duração elevada, não proporcional ao estímulo frente ao qual o indivíduo se encontra, é possível dizer que se está diante de um quadro patológico, de um transtorno de ansiedade. Em relação aos transtornos de ansiedade, o DSM-IV (2002) classifica 14 tipos diferentes de transtornos que podem ser enquadrados nessa categoria, sendo que, para este trabalho, é interessante destacar o transtorno de ansiedade generalizada, por ser esse o transtorno que apresenta sintomas mais próximos aos sintomas apresentados pela paciente objeto deste estudo. De acordo com o DSM-IV, o transtorno de ansiedade generalizada se caracteriza por:

...uma ansiedade ou preocupação excessiva (expectativa apreensiva), ocorrendo na maioria dos dias por um período de pelo menos 6 meses... O indivíduo considera difícil controlar a preocupação. A ansiedade e a preocupação são acompanhadas de pelo menos três sintomas adicionais, de uma lista que inclui inquietação, fatigabilidade, dificuldade em concentrar-se, irritabilidade, tensão muscular e perturbação do sono... embora os indivíduos com transtorno de ansiedade generalizada nem sempre sejam capazes de identificar suas preocupações como "excessivas", eles relatam sofrimento subjetivo devido a constante preocupação, têm dificuldade em controlar a preocupação, ou experimentam prejuízo no funcionamento social ou ocupacional ou em outras áreas importantes... A intensidade, duração ou freqüência da ansiedade ou preocupação são claramente desproporcionais à real probabilidade ou impacto do evento temido. (DSM-IV, 2002, p. 457)

Ainda sobre as principais características apresentadas nos transtornos de ansiedade, é interessante destacar Homes (1997), que indica que, nesses casos, os indivíduos apresentam sintomas específicos nos campos somático, motor, no do humor e no da cognição. Em relação aos sintomas de humor, o sofrimento advindo da ansiedade tem a característica de apresentar um sentimento constante de que o indivíduo será condenado por algo, ou que algo terrível irá acontecer; desse modo, o indivíduo pode apresentar sensações de tensão, medo, irritabilidade e depressão. Os sintomas cognitivos, por sua vez, dizem respeito à apreensão e/ou preocupação com uma possível condenação ou desastre que pode vir a ocorrer e que o indivíduo antecipa.

Os sintomas somáticos, de acordo com Homes, podem ser divididos em dois tipos; os primeiros podem ser chamados de imediatos, que podem ser boca seca, suor, respiração curta, sensações de tensão muscular, latejo na cabeça, pulso rápido e aumento de pressão sanguínea. Já os segundos são resultantes de um estado crônico de ansiedade, que pode debilitar o sistema fisiológico ocasionando fadiga geral, sofrimento intestinal, fraqueza muscular, hipertensão e constantes dores de cabeça. Por fim, os sintomas motores dizem respeito à impaciência e à inquietação que indivíduos em estados ansiosos podem apresentar, sendo comum que pessoas nesse estado emitam rápidos e repetidos movimentos com dedos, pés ou pernas ou respostas de susto muito exageradas a estímulos como ruídos ou presença súbita de pessoas.

\section{Compreensão do fenômeno ansiedade pelo referencial teórico da medicina tradicional chinesa - acupuntura}

A palavra ansiedade é uma palavra ocidental que se refere a um estado somato-psíquico descrito pela Psicologia e pela Medicina ocidentais. Nesses termos, a terminologia ansiedade não é uma terminologia oriental, portanto, na literatura clássica da Medicina Tradicional Chinesa (MTC), é impossível encontrar descrições de tratamentos para 
ansiedade. Aliado a isso, na MTC, não existe separação entre mente, corpo e espírito, portanto, não existem classificações de doenças ou distúrbios exclusivamente psicológicos ou psiquiátricos, como ocorre no ocidente, como, por exemplo, no caso de transtornos de ansiedade.

Entretanto, de acordo com Ling-Shu (1995), na MTC, existe uma classificação de doenças nas quais se enquadram as patologias que apresentam maior sintomatologia psíquico/ emocional, as chamadas dian-kuang, que podem ser traduzidas por perturbações mentais. Nas dian-kuang, porém, estão enquadradas as patologias mais severas, o que, no ocidente, pode ser traduzido por psicoses. Assim sendo, distúrbios menos intensos, como, por exemplo, estados ou transtornos de ansiedade, não poderiam ser classificados como patologias dian-kuang.

Nessa perspectiva, autores como Campiglia (2004) e Auteroche e Navailh (1992) entendem que fenômenos como a ansiedade são sintomas (assim como no ocidente) de distúrbios de outra ordem. Aliado a isso, como na MTC não existe separação entre corpo, mente e espírito, uma desarmonia em um dos cinco principais órgãos do corpo (na perspectiva chinesa: coração, baçopâncreas, pulmão, rins e fígado) ocasionará automaticamente um desequilíbrio nos aspectos mentais e espirituais desses órgãos, chamados respectivamente de shen, hun, po, yi e zhi.

Nessa perspectiva, como a ansiedade é sintoma de uma desarmonia, ela pode ser sintoma de desequilíbrio de qualquer um desses aspectos, sendo, porém, mais marcadamente considerada um distúrbio do shen, que significa espírito (Campiglia, 2004), ressaltando-se que, para os chineses, o espírito reside no coração. Esse espírito não fica preso no coração, mas circula por todo o corpo, garantindo a vitalidade e a consciência, regulando o humor e a sensação de bem-estar no mundo, como destaca Campiglia (2004):
O Shen aloja-se no coração. O coração é o órgão que funciona como receptáculo das funções ativas da consciência, ele abriga ou expressa sentimentos, emoções, desejos mais profundos, imaginação, intelecto e memória dos eventos passados. Como um copo ou cálice, o coração contém o sangue e o Shen, que são seu conteúdo, seu vinho sagrado... Ou seja, ao se alojar no coração, o Shen não está em um lugar fixo, mas circula como o sangue nos vasos. Ele está em todo o corpo, pois o sangue dos vasos irriga tudo, da pele aos olhos. O Shen é, portanto, uma atividade dinâmica que está na essência do coração. Adquire-se e desenvolve-se a consciência interagindo com o mundo e com os próprios órgãos e o Shen está presente em cada um deles. (p 92)

Assim, para os chineses, um distúrbio no coração corresponde automaticamente a uma desarmonia no espírito. A ansiedade, então, pode ser entendida como o resultado de uma desarmonia do espírito, seja por uma situação de excesso, insuficiência ou estagnação de qi (energia) ou xue (sangue) no coração ou em outros órgãos que acabam afetando o coração. Essa situação de excesso, insuficiência ou estagnação pode ser causada pelos seis fatores patogênicos externos, vento, frio, calor, umidade, secura e fogo; pelos sete fatores internos, alegria, raiva, tristeza, pesar, preocupação, medo e pavor, ou pelos fatores nem internos nem externos, como a alimentação, os traumas, o excesso de trabalho, de exercícios físicos ou de relações sexuais (Campiglia, 2004; Chonghuo, 1993). Embora não existam na literatura clássica da MTC referências específicas ao fenômeno ansiedade, a não ser como um sintoma de distúrbios nos cinco órgãos, mais preponderantemente no coração, já existem autores modernos, como Ross, que traçam um paralelo mais direto entre as terminologias ocidental e oriental. Para Ross (2003, p. 461), a ansiedade "pode ser definida como um estado subjetivo desagradável e inquieto de tensão e apreensão, no qual é difícil relaxar ou encontrar calma e paz".

Tomando como base o princípio chinês da indissociabilidade entre corpo, mente e espírito e da relação entre os cinco órgãos, 
A ansiedade pode então vir combinada de sobressaltos e receio, com sinais físicos como tremor, freqüência urinária ou intestinos soltos" (Ross, 2003, p. 464).
Ross (2003) também enfatiza que a ansiedade é causada por uma perturbação do sistema do coração. O autor acrescenta que o surgimento de distúrbios de ansiedade está relacionado constantemente a um desequilíbrio entre os sistemas do coração e do rim: "A ansiedade do coração está baseada no medo do rim, com sentimentos característicos de apreensão, do medo de que algo terrível aconteça. A ansiedade pode então vir combinada de sobressaltos e receio, com sinais físicos como tremor, freqüência urinária ou intestinos soltos" (Ross, 2003, p. 464).

De acordo com o autor, a ansiedade é o resultado de um distúrbio do shen, é um sintoma que indica que o espírito não está conseguindo se mover de modo adequado pelo corpo. Nesse sentido, Ross (2003, p. 465) afirma que, na perspectiva chinesa, existem pelo menos três tipos diferentes de ansiedade, de acordo com a situação que a originou:

Ansiedade por excesso: “...O fogo fleuma do coração é uma forma de excesso que pode levar à ansiedade e à confusão de pensamento, linguagem e comportamento. Consiste, essencialmente, em fleuma, decorrente da deficiência do baço, em combinação com o fogo do coração. Pode surgir de um estresse emocional ou do excesso de fumo, do álcool e de alimentos gordurosos, com falta de exercícios físicos".

Ansiedade por estagnação: "A estagnação pode dar origem ao distúrbio do movimento. A estagnação do qi do coração e do qi do fígado, por exemplo, decorrentes da estagnação emocional, podem levar ao distúrbio do espírito do coração e à hiperatividade do yang do fígado, levando à ansiedade. A estagnação do qi pode resultar em acúmulo de fleuma, que pode perturbar a livre circulação do espírito, causando ansiedade".

Ansiedade por deficiência: "a ansiedade aumenta quando a energia está reduzida, quando há deficiência por falta de sono e descanso, excesso de trabalho, estresse, doença e nutrição deficiente, além de outros fatores. A deficiência do qi do coração e do rim, do yin do coração e do rim, e do sangue do coração e do baço podem dar origem à ansiedade, já que o qi, o yin e o sangue são necessários para manter o espírito estável".

\section{Descrição da paciente tratada por meio da acupuntura tradicional chinesa}

A paciente objeto deste estudo foi uma mulher com 39 anos, casada, com três filhos, residente no interior de uma cidade com cerca de 8.000 habitantes e com economia baseada na agricultura. Quanto à profissão, refere-se a si própria como do lar, apesar de ajudar o marido na lida do campo, na plantação de milho e soja e na criação de porcos. Procurou atendimento psicológico por apresentar, de acordo com seu relato, um constante estado de ansiedade aliado a uma depressão leve, e relatou também apresentar um quadro de medo advindo de eventuais episódios de sensação de morte e uma grande preocupação com a família, embora não saiba definir em relação a que essa preocupação se apresentava.

A paciente relatou que, há 9 anos, apresentou um quadro de depressão diagnosticado por um médico clínico geral da cidade onde morava, e realizou tratamento com antidepressivos por 3 anos, apresentando um relativo alívio dos sintomas. Desde então, utilizou um antidepressivo natural chamado Ipérico, porém este também ocasionava apenas a supressão temporária dos sintomas, tendo de ser consumido com bastante regularidade.

Durante as crises, a paciente relatou que ficava extremamente sensível, com sensação de peso no corpo e na cabeça, afirmando sentir mais os sintomas no período noturno, principalmente antes de dormir. Afirmou também que sentia pressão no peito, com 
dificuldade para encher o pulmão, ficava agitada mentalmente, ao mesmo tempo em que apresentava apatia para realizar as atividades do cotidiano e sem capacidade de traçar perspectivas para o futuro. A ocorrência dos sintomas era constante (todos os dias), e eram aliviados apenas com o uso da medicação; entretanto, ressaltou que existia uma pequena acentuação dos sintomas pela manhã, quando acordava, e à noite, quando ia dormir.

Em relação ao início de suas preocupações e sensações desagradáveis, informou que surgiram quando tinha aproximadamente 13 anos; o pai, que tinha câncer, estava sempre doente, e a paciente ficava constantemente com medo de sua morte. A paciente não acredita que os seus sintomas atuais tenham ligação direta com o pai, que morreu quando ela tinha 22 anos. Afirmou, porém, que os mesmos começaram a surgir com intensidade, quando tinha 27 anos e depois que um tio, que era muito parecido com o pai, também morreu. De acordo com a paciente: "estávamos enterrando o pai pela segunda vez".

A partir dos relatos feitos pela paciente nas entrevistas iniciais, relacionou-se a sua fala com o que está descrito no DSM-IV (2002), e foi possível identificar que a mesma apresentava características de um transtorno de ansiedade generalizada. Além disso, a paciente se caracterizava também por ser uma pessoa bastante simples, com pouca instrução formal, o que, por vezes, dificultava a exposição de seus sentimentos, sendo suas falas bastante sucintas e as respostas às perguntas geralmente monossilábicas. Tais características constituíram um elemento que dificultou a realização de atendimento psicológico baseado exclusivamente em um tratamento pela fala, razão pela qual se ofereceu à paciente a possibilidade de realizar um tratamento complementar utilizando-se a técnica da acupuntura, que foi aceita.

Em relação a aspectos gerais da paciente, dentro de um padrão de diagnóstico pela acupuntura, a mesma afirmava não gostar muito do frio, preferindo o calor; apresentava bastantes calafrios, principalmente quando estava nervosa, e não costumava ter febres nem transpirar com facilidade; apresentava boa digestão e sua sede era normal; não sentia nenhum sabor mais acentuado e tinha bom sono, entretanto, apresentava sonhos repetitivos quando estava deprimida; eram sonhos recorrentes, que geralmente envolviam desastres, como aviões caindo perto de casa. Quanto à urina, apresentava cor, volume e frequência normais; o mesmo em relação aos intestinos e ao ciclo menstrual. Em relação aos órgãos dos sentidos, apresentava apenas leve dificuldade para enxergar de perto.

\section{Resumo clínico da doença - o diagnóstico pela medicina tradicional chinesa e princípios de tratamento por intermédio da acupuntura}

Com base nas entrevistas realizadas com a paciente e na apalpação dos pulsos, que apresentavam, principalmente, sinais de coração em excesso e baço deficiente ou estagnado e rim bastante deficiente, levantou-se a hipótese diagnóstica, dentro da perspectiva da medicina tradicional chinesa, de que a ansiedade ocorria, de acordo com Auteroche e Navailh (1992), Ross (2003) e Chonghuo (1993), por excesso de fogo no coração, e, possivelmente, fleuma por insuficiência do baço, que, nessa situação, não conseguia retirar a umidade adequadamente. Essa hipótese foi reforçada pelo exame da língua, que constantemente se apresentava grossa, redonda, edemaciada, sem saburra, com marcas de dentes e com petéqueas na região correspondente ao coração.

Além disso, foi possível ainda fazer uma conjetura utilizando a teoria dos cinco elementos descrita por Yamamura (2001) e Xinong (1999), estabelecendo suposições que, devido a traumas emocionais sofridos, como, por exemplo, uma contínua tristeza 
e frustração devido à doença e morte do pai e, posteriormente, do tio, a paciente tivesse elevado intensamente o receio e a preocupação consigo mesma e com a família, o que continuamente foi debilitando o baço ao longo dos anos. Com o baço debilitado, esse começou a exigir mais energia do coração, o que fez com que o fogo do mesmo ficasse elevado. A deficiência do baço e a própria tristeza e magoa contínua podem ter debilitado o pulmão, o que contribuiu para agredir ainda mais o rim, também debilitado pelo receio.

Nessa perspectiva, com o coração em excesso e o rim debilitado, a água do rim não conseguiu mais controlar o fogo do coração, e o shen ficou agitado, surgindo então os sintomas característicos da ansiedade (fenômeno assim denominado no ocidente). Assim sendo, para reverter esse quadro, optou-se essencialmente pelo tratamento recomendado na medicina tradicional chinesa, por Auteroche e Navailh (1992), Ross (2003) e Chonghuo (1993), que é "acalmar o coração, remover a estagnação do baço e fortalecer o baço e o rim" por meio da inserção de agulhas em pontos específicos do corpo que, combinados, apresentam essa finalidade, ou seja, pela acupuntura.

\section{Relato do caso - método do tratamento realizado e explicação dos princípios e pontos utilizados}

No tratamento dos sintomas da paciente, foram utilizados os pontos de acupuntura abaixo relacionados, que apresentam (dentre outras) as seguintes funções de acordo com Focks (2005) e Ross (2003):

R3 - (terceiro ponto do canal de energia do rim) Regula o equilíbrio do yin e do yang, fortalece e estabiliza a mente e as emoções, equilibra a labilidade emocional, a deficiência do qi do rim; tonifica o rim e beneficia a essência e tonifica o sangue.
R6 - (sexto ponto do canal de energia do rim) Tonifica o yin do rim, a deficiência do rim, nutre o yin, principalmente quando existe excesso de fogo no coração, promove o sono e os fluidos corpóreos.

C7 - (sétimo ponto do canal de energia do coração) Tonifica o coração, equilibra o yin e o yang, estabiliza o coração, clareia a mente, acalma a mente e as emoções, regula o espírito, tonifica o sangue, tonifica o yin do coração, elimina o fogo.

CS6 - (sexto ponto do canal de energia do coração/sexualidade) Move a estagnação e acalma irregularidades do qi, remove a estagnação de sangue e fleuma, acalma o espírito, remove a estagnação do qi do pulmão, tonifica o coração; é indicado para dor, choque e traumatismo.

CS7 - (sétimo ponto do canal de energia do coração/sexualidade) Acalma o espírito, move a estagnação e regula o qi do coração e do estômago.

E25 - (vigésimo quinto ponto do canal de energia do estômago) Regula o estresse emocional, regulariza o qi.

E36 - (trigésimo sexto ponto do canal de energia do estômago) Fortalece o baço e o estômago para produzirem qi e sangue, que eliminam a umidade; faz subir o qi, tonifica o sangue e o qi, estabiliza a mente e as emoções, regulariza o qi defensivo e nutritivo.

P5 - (quinto ponto do canal de energia do pulmão) Resfria e acalma o pulmão, trata a retenção de fleuma no pulmão, trata a deficiência de yin no pulmão.

P7 - (sétimo ponto do canal de energia do pulmão) Expele o vento externo, fortalece o pulmão melhorando a circulação do qi defensivo, remove a estagnação do qi do pulmão, remove as emoções estagnadas do pulmão, como a tristeza e a mágoa reprimidas. 
P9 - (nono ponto do canal de energia do pulmão) Tonifica o qi do pulmão, tonifica o yin do pulmão, fortalece os vasos sanguíneos e a circulação do sangue.

IG4 - (quarto ponto do canal de energia do intestino grosso) Remove o vento exterior, remove o calor, relaxa a tensão muscular, move estagnações do sangue, acalma a hiperatividade do yang do fígado, acalma a mente, tonifica o qi e o sangue.

IG11 - (décimo primeiro ponto do canal de energia do intestino grosso) Expele o vento exterior, remove o calor, relaxa a tensão muscular e alivia a dor, acalma a hiperatividade do yang do fígado, resolve a umidade.

F3 - (terceiro ponto do canal de energia do fígado) Move a estagnação do qi e do sangue, acalma a hiperatividade do yang do fígado, elimina o vento do fígado e reduz espasmos e dor; tonifica o sangue e acalma o espírito.

F14 - (décimo quarto ponto do canal de energia do fígado) Move a estagnação do qi do fígado, elimina a umidade calor do fígado; utilizado para congestionamento mental e emocional.

VC4 - (quarto ponto do canal de energia do vaso da concepção) Fortalece o jing, o qi, o yin e o yang do rim, dispersa a estagnação do qi.

VC6 - (sexto ponto do canal de energia do vaso da concepção) Tonifica a deficiência e move a estagnação do qi.

VC12 - (décimo segundo ponto do canal de energia do vaso da concepção) harmoniza a preocupação e a insegurança, tonifica a deficiência do qi e do yang do baço, move a estagnação e regula a rebelião do qi do estômago.

VC15 - (décimo quinto ponto do canal de energia do vaso da concepção) Acalma o espírito quando este está agitado pelo fogo do coração ou obstruído pela fleuma no coração.

VC17 - (décimo sétimo ponto do canal de energia do vaso da concepção) Dispersa a estagnação do qi, remove a estagnação do qi do coração, do sangue do coração, do qi do pulmão e do aquecedor superior.

BP3 - (terceiro ponto do canal de energia do baço-pâncreas) move a estagnação do qi do baço, tonifica a deficiência e fortalece o baço, resolve o esgotamento e o embotamento mental por umidade e fleuma.

BP6 - (sexto ponto do canal de energia do baço-pâncreas) Tonifica o baço, o qi e o sangue, elimina a umidade, tonifica o yin, acalma a mente, regula o qi do fígado.

BP9 - (nono ponto do canal de energia do baço-pâncreas) Elimina a umidade.

TA4 - (quarto ponto do canal de energia do triplo aquecedor) Tonifica a deficiência do qi do rim, remove o excesso do vento e calor e a estagnação do qi.

TA5 - (quinto ponto do canal de energia do triplo aquecedor) Remove vento e calor e a estagnação do qi do fígado.

Yintang - (ponto extra localizado no entre as sobrancelhas) Acalma a mente, diminui cefaléia, tonturas e a sensação de peso na cabeça; é utilizado em casos de estados de ansiedade, de distúrbios do sono e em estados de confusão mental.

A seleção e a utilização desses pontos ocorreram a partir de breve investigação oral da paciente e do exame dos pulsos e da língua em cada sessão. Dentro da perspectiva teórica da acupuntura, é possível identificar a qualidade da energia qi dos órgãos do corpo, a saber, pulmão, baço-pâncreas, ming men (órgão da medicina chinesa correspondente a um dos rins), coração, fígado e rim, por intermédio do exame dos pulsos do 
paciente (Auteroche \& Navailh, 1992; Flaws, 2005; Yamamura, 2001; Xinong, 1999). Procedimento semelhante pode ser realizado pelo exame da língua, que apresentará, em áreas específicas (correspondentes aos órgãos do corpo), sinais como edemas, palidez, vermelhidão, rachaduras, saburras de diversas espessuras e tonalidades (Maciocia, 2003; Xinong, 1999). A partir do exame da língua e dos pulsos, a qualidade da energia de cada órgão pode ser classificada como normal, em excesso, estagnada, deficiente ou inexistente, sendo que cada uma dessas características acarretará uma sintomatologia diferenciada no paciente, que é tratado com a estimulação, a sedação ou a harmonização de pontos de acupuntura específicos (Maciocia, 2003).

A estimulação de um ponto de acupuntura é feita com a inserção da agulha no mesmo sentido do fluxo do canal de energia, deixando-se a agulha inserida no corpo por um tempo reduzido, aproximadamente 10 a 15 minutos. Já a sedação do ponto é feita de modo oposto: a agulha é inserida no sentido contrário ao fluxo de energia do canal, e é deixada por tempo maior, mais de 30 minutos. Por sua vez, a harmonização de um ponto de acupuntura é feita com a inserção perpendicular da agulha no canal de energia, e a mesma é deixada por um tempo médio, de 20 a 25 minutos (Auteroche \& Auteroche, 1996; Chonghuo, 1993; Xinong, 1999). Nesse tratamento, foram realizadas 10 sessões de acupuntura, realizadas inicialmente uma vez por semana, com duração média de 50 minutos; entretanto, a paciente já relatava alguma melhora dos sintomas a partir da quarta sessão. Como caráter ilustrativo, segue a descrição geral dos pulsos da paciente e dos pontos utilizados durante as sessões de acupuntura.

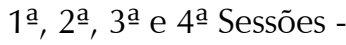

Situação geral dos pulsos:

Pulmão: normal

Coração: excesso

Baço-pâncreas: deficiente Fígado: deficiente

Ming Men: inexistente
Diferentes pontos utilizados ao longo das sessões:

R3, R6, E36, BP3, BP6, P5, BP9, P7, VC4 e VC12 - Tonificando, para fortalecer o rim, nutrir o sangue, retirar a umidade e fortalecer o baço, melhorar a absorção e a circulação do qi, fortalecer o pulmão, equilibrar as emoções e remover estagnações.

F3, C7, CS6, CS7, IG4 - Harmonizando, para estabilizar as emoções, harmonizar o coração, o sangue o qi e o shen.

A partir da quarta sessão, a paciente relatou uma significativa diminuição dos sintomas que a trouxeram ao atendimento, informou sentir grande alívio das sensações desagradáveis que sentia antes e que agora apresentava uma permanente sensação de tranquilidade.

5ํㅡ e 6 ${ }^{\underline{a}}$ Sessões - Situação geral dos pulsos:

Pulmão: normal Coração: excesso Baço-pâncreas: inexistente Fígado: deficiente Ming Men: inexistente Rim: deficiente Diferentes pontos utilizados ao longo das sessões:

VC4, P7, BP3, BP6, BP9, E36, R3 - Tonificando, para fortalecer pulmão, baço e rim, tonificar e melhorar a circulação de qi e xue.

F3, F14, CS6, CS7, IG4, C7, E25, VC17, VC12 - Harmonizando, para retirar obstruções e estagnações do fígado, harmonizar o coração e o shen, regular as emoções e melhorar a circulação de qi e xue.

Na sexta sessão, a paciente relatou ter suspendido por decisão própria a utilização do antidepressivo natural que estava utilizando. Declarou que estava se sentido muito melhor desde que havia começado o tratamento, e acreditava que não haveria mais necessidade de realizar uma sessão por semana, tendo sido acordado que, a partir de então, as sessões iriam ocorrer a cada 15 dias. A partir desse momento, o principal foco do tratamento foi o de manter o padrão alcançado, a fim de evitar novo surgimento dos sintomas.

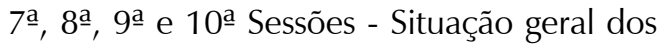
pulsos 
Pulmão: normal

Coração: normal

Baço-pâncreas: deficiente

Fígado: normal

Ming Men: deficiente

Rim: deficiente

Pontos utilizados:

P7, E36, BP6, BP9, VC6, VC12, BP3 Tonificando, para fortalecer o rim, o qi e o xue e remover estagnações.

R3, F3, TA5, VC6, VC15, E25, IG4, C7, Yintang - Harmonizando, para manter o fluxo suave do qi e do xue, retirar estagnações e manter a estabilidade das emoções.

\section{Discussão}

A medicina tradicional chinesa entende que a maioria dos distúrbios emocionais e psíquicos tem em sua base uma desarmonia entre as energias dos diversos órgãos do organismo, com especial destaque para as energias do coração e do rim (Auteroche \& Navailh, 1992; Chonghuo, 1993; Ross, 2003). Isso fica claro quando se observa que, no entendimento chinês, distúrbios emocionais ou psíquicos são demonstrações de distúrbios do espírito (shen) do indivíduo, sendo que, em chinês, a palavra shen tanto significa espírito quanto rim, e que o coração (xin) é o lugar de moradia do espírito (shen). Nesse sentido, é possível fazer a leitura metafórica de que o espírito não consegue encontrar condições adequadas para habitar a sua morada, por isso fica conturbado, e essa perturbação se manifesta por sintomas como, por exemplo, aqueles típicos da ansiedade descritos pela Psicologia e pela medicina ocidentais.

No caso da paciente em questão, a desarmonia foi observada por meio de entrevistas e de técnicas próprias da acupuntura, como a palpação do pulso e o exame da língua. Após a delimitação do diagnóstico, o tratamento visou a restabelecer o equilíbrio do espírito, tendo como base os protocolos de tratamento indicados por Auteroche e Navailh (1992), Ross (2003) e Chonghuo (1993). Por essa razão, a base do tratamento foi harmonizar o coração e fortalecer o pulmão e o baço, para melhorar a absorção de qi (energia) e a circulação do qi (energia) e do xue (sangue) para assim fortalecer o rim e restabelecer o equilíbrio entre este e o coração.

É importante destacar que o tratamento realizado por meio da acupuntura não proporciona curas milagrosas ou o fim total das patologias dos pacientes, como destacam Campiglia (2004), Ross (2003) e Vectore (2005). O tratamento pela acupuntura ocorre de modo processual, sendo que o restabelecimento da saúde se dá de modo gradual e está diretamente relacionado a condições externas (ambientais, climáticas, sociais e históricas) e internas (alimentação, estados emocionais, espiritualidade), com as quais o sujeito se relaciona (Campiglia, 2004; Vectore, 2005). Um exemplo de que o tratamento é processual, e não final e definitivo, pode ser observado nas últimas sessões realizadas, na quais, apesar de a paciente não mais relatar sentir os sintomas que a trouxeram ao tratamento, ainda apresentava alterações nos pulsos.

\section{Conclusão}

Como referido, a acupuntura não é uma técnica que propicia curas milagrosas de nenhum tipo de patologia que se pretende tratar; em vez disso, o restabelecimento da saúde é sempre realizado por um processo contínuo e gradual. No caso do tratamento em questão, esse restabelecimento gradual pôde ser notado a partir do relato da paciente, que afirmou ter apresentado melhora dos sintomas a partir da quarta sessão de acupuntura, o que correspondeu a um mês de tratamento. Com a continuidade dos atendimentos, a partir da sexta sessão, a paciente realizou por conta própria a suspensão dos medicamentos que usava, e relatou a redução significativa dos sintomas iniciais, decidindo continuar com o contrato mínimo pré-estabelecido das dez sessões para melhorar ainda mais o equilíbrio obtido.

Por se tratar de uma sintomatologia bastante antiga, foi aconselhado à paciente que mantivesse uma regularidade das sessões de 
acupuntura após o tratamento inicial ou que continuasse com algum acompanhamento psicológico, visto que o tratamento basicamente realizou a diminuição da intensidade dos sintomas apresentados, não podendo ser atribuída uma cura definitiva. Desde então, a paciente não apresentou mais os sintomas na mesma intensidade que apresentava no início das sessões de acupuntura, sendo que, atualmente, continua realizando acompanhamento pela acupuntura com uma sessão por mês, apenas em caráter preventivo e para a manutenção do seu bemestar geral.

\section{André Luiz Picolli da Silva}

Psicólogo, Mestre em Psicologia pela Universidade Federal de Santa Catarina, Florianópolis, SC - Brasil. Especialista em Acupuntura pelo Instituto Brasileiro de Acupuntura e Moxabustão de Porto Alegre, Porto Alegre, RS - Brasil. Professor de Psicologia da Universidade Federal do Pará - Campus de Marabá, Marabá, PA - Brasil.

Endereço para envio de correspondência:

Rua São Francisco, n² 2401 apt. "B" - Bairro Cidade Nova - Marabá, PA - Brasil - CEP: 68501-690

E-mail: anpicolli@yahoo.com.br

Recebido 27/11/2008, 1a Reformulação 7/8/2009, 2a Reformulação 25/8/2009, Aprovado 15/9/2009.

\section{Referências}

Auteroche, B., \& Navailh, P. (1992). O diagnóstico na medicina chinesa. São Paulo: Andrei.

Auteroche, B., \& Auteroche, M. (1996). Guia prático de acupuntura e moxabustão. São Paulo: Andrei.

Campiglia, H. (2004). Psique e medicina tradicional chinesa. São Paulo: Roca.

Chonghuo, T. (1993). Tratado de medicina chinesa. São Paulo: Roca.

Conselho Federal de Psicologia (2002). Resolução no 05/2002 - Dispõe sobre a prática da acupuntura pelo psicólogo.

DSM-IV. (2002). Manual diagnóstico e estatístico de transtornos mentais (C. Dornelles, Trad., 4a ed. rev.). Porto Alegre: Artmed.

Flaws, B. (2005). O segredo do diagnóstico pelo pulso (C. da S. Garrido, Trad.). São Paulo: Roca.

Focks, C. (2005). Atlas de acupuntura: com seqüência de fotos e ilustrações, textos didáticos e indicações clínicas. Barueri, SP: Manole.

Homes, D. S. (1997). Psicologia dos transtornos mentais (S. Costa, Trad., 2a ed.). Porto Alegre: Artes Médicas.
Kaplan, H. I., Sadok, B. J., \& Greb, J. A. (1997). Compêndio de psiquiatria: ciências do comportamento e psiquiatria clínica (D. Batista, Trad., 7aed.). Porto Alegre: Artmed.

Ling-Shu. (1995). Base da acupuntura tradicional chinesa (Ming Wong, Trad.). São Paulo: Andrei.

Maciocia, G. (2003). Diagnóstico pela língua na medicina chinesa (M. I. Garbino Rodrigues, Trad.). São Paulo: Roca.

Ross, J. (2003). Combinações dos pontos de acupuntura: a chave para o êxito clínico. São Paulo: Roca.

Silva, D. F. da. (2007). Psicologia e acupuntura: aspectos históricos, políticos e teóricos. Psicologia: Ciência e Profissão, 27(3), 418-429.

Vectore, C. (2005). Psicologia e acupuntura: primeiras aproximações. Psicologia: Ciência e Profissão, 25(2), 266-285.

Xinong, C. (1999). Acupuntura e moxabustão chinesa (E. I. Souza Martins, Trad.). São Paulo: Roca.

Yamamura, Y. (2001). Acupuntura tradicional: a arte de inserir (2aed.). São Paulo: Roca. 